\title{
OS E-BOOKS NAS COLEÇÕES DE BIBLIOTECAS ESCOLARES: SUBSÍDIOS PARA ELABORAÇÃO DA POLÍTICA DE AQUISIÇÃO
}

\author{
E-LIBROS EN LAS COLECCIONES DE BIBLIOTECAS \\ ESCOLARES: SUBVENCIONES PARA LA ELABORACIÓN DE LA \\ POLÍTICA DE CONTRATACIÓN
}

\begin{abstract}
Ivone Guerreiro Di Chiara - dichiara@uel.br Mestre em Ciência da Informação pela Universidade Federal de Minas Gerais (UFMG). Professora do Departamento de Ciência da Informação da Universidade Estadual de Londrina (UEL).

Elaine Cristina Liviero Tanzawa - tanzaw@hotmail.com Mestre em Educação pela Universidade Estadual de Londrina (UEL). Especialista em Gestão de Biblioteca Escolar pela Universidade Estadual de Londrina (UEL). Bibliotecária do Instituto Cultural Brasil - Estados Unidos
\end{abstract}

\section{RESUMO}

Introdução: O documento eletrônico como novo suporte informacional tem exigido das bibliotecas mudanças em relação à política de aquisição bem como a necessidade de se colher subsídios para elaboração dessa política, o que motivou a realização desse estudo.

Objetivo: Estabelecer subsídios que auxiliem na elaboração da política de aquisição de e-books para bibliotecas escolares.

Metodologia: pesquisa bibliográfica tendo como fontes as bases de dados mais importantes da área da Ciência da Informação. Os textos selecionados foram artigos de periódicos, livros, teses, dissertações e trabalhos apresentados em eventos no período de 2000 a 2013.

Resultados: Foi possível identificar todos os cuidados que se deve ter quando da aquisição de ecoleções, principalmente nos contratos de licenciamento, os fornecedores e os modelos de negócios utilizados para aquisição desse tipo de material, principalmente e-books.

Conclusões: As informações apresentadas e analisadas poderão servir de subsídios para elaboração de uma política de aquisição de e-books, considerando-se que embora esse suporte 

aquisição

tenha as suas próprias características, os procedimentos para aquisição dos materiais que compõem as e-coleções são similares.

Palavras Chave: Livros eletrônicos. Política de desenvolvimento de coleções. Política de aquisição. Planejamento de coleções eletrônicas. Bibliotecas escolares.

\section{INTRODUÇÃO}

A escolha de um suporte novo de material em uma biblioteca, o eletrônico, exige uma maneira nova de pensar e planejar a sua aquisição, manutenção e acesso. Desta forma, devem-se estabelecer procedimentos para o desenvolvimento de coleção, o que não constitui uma tarefa fácil devido ao grande número de recursos eletrônicos disponíveis. Por este motivo, o planejamento da sua seleção, aquisição e avaliação deve ser pautado em critérios bem definidos.

Os bibliotecários têm diante de si difíceis dilemas para solucionar quando, por exemplo, precisam decidir entre coleções impressas e digitais, entre fontes de acesso pago ou livre e sobre os desígnios das coleções retrospectivas impressas frente as pressões por mais espaços e menos custo de armazenamento e manutenção deste tipo de material. (WEITZEL, 2006, p. 8).

Nesse contexto, Dias, Silva e Cervantes (2012, p. 3) ainda nos alertam que

[...] devemos considerar que a coleção deve ser desenvolvida com base em um plano pré-estabelecido que garanta sua continuidade e adequação necessárias à formação da coleção. Para que a coleção seja multidisciplinar e atenda de maneira eficaz aos usuários de todas as áreas do conhecimento.

O dilema que o bibliotecário precisa administrar com relação ao desenvolvimento de coleção inspirou este estudo, que tem como objetivo estabelecer subsídios que poderão auxiliar no planejamento da aquisição de e-books em bibliotecas escolares, ou seja, levantar subsídios para elaboração da política de aquisição. Para tanto, foi necessário identificar, coletar, sistematizar e analisar informações que possam nortear este planejamento. A metodologia recomendada para atingir este objetivo foi a pesquisa bibliográfica, pois esta permite localizar contribuições teóricas existentes sobre um determinado assunto ou problema. 

aquisição

Uma coleção eletrônica pode oferecer uma gama enorme de recursos que podem ser disponibilizados pelas bibliotecas, tais como: periódicos, livros, bases de dados, documentos digitalizados, web sites, etc. Diante desta diversidade de fontes foi necessário delimitar este trabalho a um único recurso eletrônico: os e-books em bibliotecas escolares.

O livro eletrônico, tema deste estudo, é oferecido às bibliotecas como uma opção para a realização de leituras e estudos. Em algumas bibliotecas já se verifica um aumento no número de leitores que preferem ou escolhem ler nesse formato (MARX, 2013).

Conforme destacam Silva e Bufrem (2001, p. 1)

O livro eletrônico, em língua inglesa e-book, vem afetando uma história de cinco séculos da hegemonia do impresso. [...] É certo que este não desaparecerá tão cedo, pois está profundamente arraigado à cultura de transmissão impressa e ao uso generalizado de um amplo contingente de leitores.

Face a esse contexto, percebeu-se a necessidade de um trabalho que reunisse, por meio de pesquisa bibliográfica, orientações com relação à aquisição da coleção eletrônica em bibliotecas no âmbito escolar, razão pela qual justificou-se este estudo que teve como objetivo analisar as informações disponíveis na literatura para nortear o planejamento da aquisição da coleção eletrônica, especificamente e-books.

Planejar e implementar uma biblioteca de escola que se adapte perfeitamente às necessidades dos alunos e professores e, ao mesmo tempo, efetivamente promova o uso da informação, competência informacional e leitura não é fácil (CORBETT, 2011), quanto mais incorporar a esta vasta missão materiais em diferentes formatos e meios.

\section{A BIBLIOTECA NO ÂMBITO DA ESCOLA}

A biblioteca escolar, nas décadas de 30 e 40 do século XX, passa a ser incluída no processo de reforma educacional, principalmente construindo uma valorização educativa e de estímulo ao processo de ensino/aprendizagem, tendo como finalidade prioritária a intensificação do gosto pela leitura. No entanto, é somente na década de 70 do século XX que ela começa a adquirir o conceito que se tem hoje em que a biblioteca é um dos suportes da educação, como explica Silva (2011). Hoje se trabalha sob a perspectiva da 
Ivone Guerreiro Di Chiara; Elaine Cristina Liviero Tanzawa

Os e-books nas coleções de bibliotecas escolares: subsídios para elaboração da política de aquisição

Lei no. 12.244, de 24 de maio de 2010, que dispõe acerca da universalização das bibliotecas nas instituições de ensino do país. Destacamos a lei a seguir:

\section{O PRESIDENTE DA REPÚBLICA}

Faço saber que o Congresso Nacional decreta e eu sanciono a seguinte Lei:

Art. 10 As instituições de ensino públicas e privadas de todos os sistemas de ensino do País contarão com bibliotecas, nos termos desta Lei.

Art. 2o Para os fins desta Lei, considera-se biblioteca escolar a coleção de livros, materiais videográficos e documentos registrados em qualquer suporte destinados a consulta, pesquisa, estudo ou leitura.

Parágrafo único. Será obrigatório um acervo de livros na biblioteca de, no mínimo, um título para cada aluno matriculado, cabendo ao respectivo sistema de ensino determinar a ampliação deste acervo conforme sua realidade, bem como divulgar orientações de guarda, preservação, organização e funcionamento das bibliotecas escolares.

Art. 3o Os sistemas de ensino do País deverão desenvolver esforços progressivos para que a universalização das bibliotecas escolares, nos termos previstos nesta Lei, seja efetivada num prazo máximo de dez anos, respeitada a profissão de Bibliotecário, disciplinada pelas Leis nos 4.084, de 30 de junho de 1962, e 9.674, de 25 de junho de 1998. Art. 4o Esta Lei entra em vigor na data de sua publicação.

Brasília, 24 de maio de 2010; 189o da Independência e 122o da República. (BRASIL, 2010, p. 1).

\section{O Manifesto IFLA/UNESCO para biblioteca escolar ainda alerta que}

A biblioteca escolar oferece serviços de apoio à aprendizagem, disponibilizando livros e outros recursos informacionais aos membros da comunidade escolar, possibilitando-lhes tornarem-se pessoas críticas e usuários competentes de informações em todos os formatos e meios. (INTERNATIONAL FEDERATION OF LIBRARY ASSOCIATIONS AND INSTITUTIONS, 2000, Não paginado).

O estudo de Shermer-Shalman (2008, Não paginado, tradução nossa) nas bibliotecas Israelenses sugere três possibilidades que merecem atenção.

Primeiro as bibliotecas escolares em Israel estão em fase de status quo, no entanto, há um movimento leve para o cenário de mudanças em que a biblioteca vai continuar a existir, mas vai oferecer um mix diferente de serviços.

Segundo é a possibilidade de mudança, em que as bibliotecas continuam a existir, mas com uma missão revista e oferecendo um mix de serviços diferente.

Terceiro cenário é a obsolescência. A internet pode diminuir a necessidade de bibliotecas na medida em que elas desaparecem. 

aquisição

Assim, a biblioteca deve ser pensada como um espaço que ofereça a oportunidade do estudante interagir com diferentes suportes de informação e serviços, podendo disponibilizar tanto um acervo físico como o virtual. Desta forma, faz-se necessário a reflexão sobre o acervo eletrônico.

\section{O DESENVOLVIMENTO DE COLEÇÕES E O ACERVO ELETRÔNICO / E-BOOK}

Pensar em acervo eletrônico, em uma biblioteca, hoje, é pensar numa multiplicidade de possibilidades de acesso à informação inimaginável no passado. A biblioteca passou por vários períodos históricos que podem ser contados por meio da transmutação de seus materiais por diversos formatos e sua materialização, a qual se deu, inicialmente, por meio das tabelas de argilas, passando pelo papiro, pelo pergaminho e pelo papel, até transformar o formato impresso no formato digital ou virtual (AQUINO, 2004).

O formato eletrônico trouxe uma nova exigência tanto em relação aos próprios tipos de formatos a serem disponibilizados para seus usuários como também os serviços prestados, conforme nos demonstra Aquino (2004, p. 9) quando diz

A passagem da cultura impressa para a cultura digital afetou não só os ambientes do papel, exigindo-lhes não só sua adequação aos novos formatos, mas impondo a aquisição de novas competências e habilidades para o desenvolvimento dos serviços informacionais.

Cunha (1999), sinalizava essas mudanças quando destacou que as novas tecnologias foram, gradativamente, incorporadas às atividades das bibliotecas, provocando mudanças internas e na maneira de fornecer produtos e serviços aos usuários. Já Ferreira (1997) relatava que estudos apontavam a tendência do usuário pela busca por serviços interativos.

Ter esse novo produto disponibilizado nas bibliotecas escolares implica pensar, como explica ainda Aquino (2004), em novas ferramentas de busca, recuperação e estratégias de acesso à informação, para que desta forma, seja facilitado com rapidez 0 contato com o objeto do conhecimento em qualquer lugar e em tempo real.

Ao abordar as coleções eletrônicas, Lynch (2013) destaca alguns diferenciais ou vantagens de se disponibilizar e-books aos usuários de bibliotecas, tais como: a 

aquisição

capacidade de ajustar tamanho e fonte do texto; tecnologia que permite escutar o livro; capacidade de transportar um grande número de livros em um só aparelho. Além disso, a tecnologia elimina a necessidade de imprimir, armazenar, espaço físico, taxa de envio, transporte físico de cópias de livro. Esse mesmo autor destaca as expectativas que o ebook traz. A primeira delas está relacionada ao fato de que os e-books têm a possibilidade de disponibilizar os conteúdos de forma mais fácil e rápida; a segunda é que os e-books seriam "mais verde", ou seja, sustentáveis pelo fato de poderem dispensar a impressão; e, por último, os e-books deveriam ser mais baratos que livros impressos.

Diferentes dispositivos ${ }^{1}$ permitem a leitura em formato digital. Existem formatos ${ }^{2}$ com suas características para apresentar os conteúdos dos e-books, sendo os mais comuns são EPUB, PDF. São formatos de arquivos de texto simples, mais amplamente utilizados por editores e fabricantes de e-books. Existem alguns formatos que só podem ser lidos em livros eletrônicos específicos, tais como os fabricantes dos Kindles e Nooks, por exemplo. Um dos formatos existentes é o Open Standard: formato de arquivo que pode ser utilizado sem pagar taxas de royalties ou licenciamento. Os mais populares são: EPUB, PDF e Plain Text.

As mais importantes características dos e-books segundo Procópio (2005, p. 14, grifo do autor) estão elencados a seguir: a) Marcadores de página e busca rápida dessas marcações; b) Bloco de anotações [excelente para não se esquecer daquele trecho importante que o professor citou em sala de aula e que certamente vai cair na prova]; c) Controle de brilho e contraste; d) Controle ajustável de luminosidade [backlight que deixa o leitor ajustar a intensidade da luz, assim pode-se ler em qualquer lugar. Importante para os olhos mais sensíveis. O leitor pode, por exemplo, ler aquele romance de terror ou de suspense do Stephen King, no escuro]; e) Dicionário em várias línguas no sistema que, basta apontar uma palavra na tela [naturalmente, sensível ao toque], e o reader traz o seu significado [o link vem de um outro livro também instalado no aparelho]; f) Busca por palavras ou frases no texto [ideal para documentos técnicos, como os de Legislação e Direito]; g) $\mathrm{O}$ e-Book permite ainda sublinhar ou marcar um trecho importante no texto, podendo, quando quiser, apagar a marcação; h) Ajuste de tamanho e tipo das fontes utilizadas, para melhorar a legibilidade; j) Base giratória de

\footnotetext{
1 A PAGINA. E-books: saiba mais sobre vantagens, incertezas e o mercado. Disponível em: <http://www.apaginadistribuidora.com.br/noticias/detalhe/c/44>. Acesso em: 2 jan. 2014.

${ }^{2}$ MONROE COUNTY LIBRARY SYSTEM. E-Books and E-Book readers. New York, 2013. Disponível em: <http:/Www3.libraryweb.org/uploadedFiles/MCLS/Download/eBook_Report.pdf>. Acesso em: 10 jan. 2014
} 

aquisição

leitura [orientação: retrato e paisagem], usada para textos especiais, como os dos jornais ou revistas tablóides, que podem ser lidos na horizontal; k) Acesso às livrarias [eBookStores] ou Bibliotecas Digitais, com a possibilidade de aquisição de obras gratuitas, impensado no modo real: mais de 350 mil títulos grátis, somente na língua portuguesa, e centenas de best-sellers e clássicos antes esgotados; I) Possibilidade de criação de biblioteca pessoal com as ferramentas de sistema; $\mathrm{m}$ ) $\mathrm{O}$ leitor pode também publicar seu próprio eBook importando documentos pessoais e da Internet, usando também as ferramentas de sistema; n) Grande capacidade de armazenamento de arquivos de textos [cerca de 250 mil páginas em média, incluindo gráficos]; o) Memória expansível; p) Tamanho de um livro de papel: 14×21 em média; q) compatível com níveis de segurança [criptografia a] exigido pelos detentores de conteúdo; r) Baterias duradouras: de 20 a 40 horas em média; s) Compatibilidade com PCs, Linux e MACs; t) Peso médio: 300 gramas.

Herther (2005 apud BALL, 2006) identificou alguns problemas e obstáculos encontrados para o efetivo fornecimento de e-books às bibliotecas: falta de um padrão aberto claro para os sistemas operacionais; medos sobre a proteção de conteúdo e os direitos do proprietário do conteúdo no contexto de oferecer aos usuários a flexibilidade; falta de conteúdo apropriado em quantidades adequadas; preços de títulos, software e hardware; falta de integração no mercado geral de livros.

Os e-books são uma parte importante do acervo de bibliotecas, mas seu fornecimento, por meio de licenciamento, não é tão simples e exige intensa negociação entre editoras, fornecedores e bibliotecas. O Brasil tem assistido países como os Estados Unidos discutir este assunto. A American Library Association (ALA) criou um grupo Digital Content \& Libraries Working Group ${ }^{3}$ (DCWG), com peritos amplamente representativos dentro da comunidade de biblioteca, que pode tratar proativamente do que é chamado de oportunidades em conteúdo digital para disseminar a informação para os usuários.

Assuntos tais como preço, licença e preservação estão em pautas de discussão (STRIPLING et al., 2013). Esse é um exemplo para as bibliotecas do Brasil e de outros países.

Para as bibliotecas disponibilizarem serviços eletrônicos devem contar com pessoal especializado, capaz de selecionar, estruturar e oferecer acesso intelectual, de forma que

${ }^{3}$ AMERICAN LIBRARY ASSOCIATION (ALA). Digital content working group. Chicago, 2011. Disponível em: <http://www.ala.org/groups/committees/special/ala-dcwg >. Acesso em: 10 jan. 2014. 

aquisição

preserve e garanta a continuidade de coleções de obras eletrônicas como os e-books, por exemplo. Devem ainda contar com políticas de desenvolvimento de coleções, sejam elas físicas ou virtuais. Como lembra Aguado de Costa (2011) o crescimento de uma biblioteca não pode ser indefinido nem tão pouco desorganizado e segundo a autora:.

É necessário contar com a formulação de políticas de gestão de coleção, aprovadas pelas mais altas autoridades da instituição. Sua existência é a segurança perante as mudanças de pessoal e a falta de continuidade de orçamentos. Sua utilidade é inegável, embora requeira uma grande quantidade de dados, em especial para determinar os pontos fracos e fortes da coleção, estudar a comunidade a que serve e as mudanças produzidas nelas, e estabelecer outros recursos de informação acessível (AGUADO DE COSTA, 2011, p. 10).

Vergueiro (1989), Evans e Saponaro (2005) e Weitzel (2013) destacam as etapas do processo de desenvolvimento de coleção. Esse processo compreende seis etapas interdependentes: A primeira etapa refere-se ao estudo da comunidade na qual a biblioteca está inserida; A política de seleção é parte da segunda etapa; A terceira etapa trata da seleção; A quarta etapa refere-se à aquisição que consiste na obtenção do material selecionado por meio de compra, permuta ou doação. Já na quinta etapa devem ser demonstrados os procedimentos para se proceder a avaliação do acervo. 0 desbastamento e o descarte são tratados na sexta etapa.

Weitzel (2013, p.43) afirma que "[...] a aquisição pode ser consideradas sob o aspecto de um processo e de uma política."

Este artigo trata especificamente da quarta etapa, a aquisição, de e-books, principalmente orientações para a sua inserção nas coleções de bibliotecas escolares, 0 que significa tratar a aquisição dos e-books sob a perspectiva da sua política.

\section{DELINEAMENTOS METODOLÓGICOS}

Para realização deste estudo, elegeu-se a pesquisa bibliográfica. Conforme destaca Gil (1999, p. 65) "A pesquisa bibliográfica é desenvolvida a partir de material já elaborado, constituído principalmente de livros e artigos científicos." Dessa forma, essa modalidade de pesquisa possibilita ampliar a proporção de conhecimento já existente de determinada área. 

aquisição

As fontes de pesquisa foram os livros, artigos de periódicos, dissertações, teses e trabalhos apresentados em eventos encontrados nas bases de dados previamente selecionadas: Literatura Brasileira em Biblioteca Escolar (LIBES) ${ }^{4}$; Base de Dados Referencial de Artigos de Periódicos em Ciência da Informação (BRAPCI) ${ }^{5}$; Periódicos da CAPES $^{6}$; EBSCO Host- Library, Information Science \& Techonology Abstracts. Library ${ }^{7}$. Essas fontes tem muita credibilidade no meio acadêmico.

Os documentos foram identificados nas bases mencionadas com os termos definidos em português: desenvolvimento de coleção digital, desenvolvimento de coleção eletrônica, aquisição de e-books, livros eletrônicos, recurso digital, recurso eletrônico, coleção digital, coleção eletrônica, biblioteca digital e biblioteca eletrônica, sempre relacionando estes termos com a biblioteca escolar. Esses termos foram transcritos para o inglês: digital collection development, electronic, collection development, e-books acquisition, electronic books, digital resources; electronic resources, digital library, digital collection. O período estabelecido para busca dos textos foi de 2000 a 2013. Os textos selecionados foram identificados e coletados até o dia 30 de dezembro de 2013.

O instrumento utilizado para a coleta de informações foi um formulário préestabelecido para cada texto selecionado, o que possibilitou a investigação do tema. Neste formulário, após a leitura de cada texto, anotou os seguintes tópicos: tema do artigo; conceitos de desenvolvimentos de coleção; critérios de aquisição de coleção eletrônica; empresas do mercado que ofereçam plataformas de livro eletrônico; modelos de negócios para aquisição; termos de uso.

\section{POLÍtica de desenVOLVIMENTO de COLEÇÕES}

Verificou-se que um único texto (KHAN; KHAN, 2010) apresentou com maior clareza o conceito de desenvolvimento de coleção. Os autores citaram Parmeshwaram (1997) que explica que o desenvolvimento de coleções inclui o planejamento para uma sistemática construção racional da coleção geral. O processo inclui várias atividades, tais como as necessidades do usuário, a avaliação da atual coleção, a determinação de uma

${ }^{4}$ Disponível em: http://libes.eci.ufmg.br/

${ }^{5}$ Disponível em: http://brapci.ufpr.br

${ }^{6}$ Disponível em: www.periodicos.capes.gov.br

Disponível em: http://web.ebscohost.com.vlib.interchange.at/ehost/search/basic?sid=426a9507-76cb4d5d-b350-c81783d528a1\%40sessionmgr10\&vid=1\&hid=11 

aquisição

política de seleção, gestão de itens selecionados, análise e armazenamento de itens incorporados e o planejamento do compartilhamento de recursos. Assim, o desenvolvimento de coleção não é uma atividade singular, mas um grupo de atividades.

No que se refere à política de desenvolvimento de coleções para materiais eletrônicos, Khan e Khan (2010) apresentam 14 componentes de uma política que devem ser observados. Conforme esses autores, a política de desenvolvimento de coleções deve cobrir a seleção, aquisição, avaliação, armazenamento, compartilhamento (de rede), preservação, conservação, uso e reuso. Assim, os vários componentes de uma política de desenvolvimento de coleções podem ser apresentados da seguinte forma: 1. objetivo da biblioteca; 2. filosofia da biblioteca; 3. breve descrição da comunidade; 4. delimitação de quem é legalmente responsável pela gestão da biblioteca e seleção de materiais; 5 . os métodos de seleção, bem como as limitações de orçamento, grupos de usuários de diferentes idades e informações semelhantes; 6 . tipo de material excluído; 7 . indicação de como a coleção deve ser construída em termos de nível de profundidade; 8. período cronológico coberto; 9. áreas geográficas abrangidas; 10. formas de materiais cobertos; 11. aquisição de materiais em língua estrangeira; 12. declaração e gestão de doações; 13. esclarecimento sobre as práticas de preservação / conservação e eliminação; 14. declaração sobre a liberdade intelectual.

\section{POLÍTICA DE AQUISIÇÃO DE E-COLEÇÕES: EM DESTAQUE OS E-BOOKS}

A inclusão de materiais eletrônicos na coleção gera a necessidade de pensar na característica de continuidade e interconectividade do formato e amplia o conceito de desenvolvimento de coleção.

Para os critérios de seleção deve-se considerar o seguinte: qualidade do título, incluindo atualidade, a cobertura tópica, reputação do autor e editor, organização, facilidade de utilização; uso antecipado; disponibilidade de material no acervo da biblioteca idêntico ou similar; disponibilidade de material idêntico ou similar nas bibliotecas para empréstimo local; custo; os requisitos de espaço ou para mídia eletrônica, requisitos técnicos; tempo necessário da equipe de manutenção, seja para depósito ou para o gerenciamento de acesso eletrônico (LASTRES, 2011).

No que se refere aos critérios de manutenção deve-se considerar o seguinte: revisão de faturas para renovação e continuidade regular para garantir que os custos 

aquisição

sejam monitorados e quais assinaturas são usadas ativamente; monitoramento métricos de circulação para verificar o uso dos meios eletrônicos e desta forma, identificar os títulos que são utilizados marginalmente; descarte dos mais materiais velhos ou ultrapassados; fornecer um relatório de orçamento detalhado para ajudar na realização de uma revisão abrangente dos recursos de biblioteca; recomendar alternativas de baixo custo de materiais impressos ou eletrônicos para que os usuários possam determinar quais materiais devem ser mantidos (LASTRES, 2011).

Ainda de acordo com Lastres, em relação ao acesso deve-se considerar o seguinte: licenças de usuário único ou simultâneo; licença limitada de usuário: obter acesso para funcionários da biblioteca para recuperar artigos eletrônicos do site do fornecedor dentro dos termos de acordo da licença; licenças empresariais: observar se tem request IP autenticação, isso elimina a necessidade dos usuários lembrar IDs de usuário e senhas; preços; verificar se o acesso a conteúdos digitais requer qualquer software proprietário.

Em obra que trata do licenciamento, Brennan et al. (2007 apud FARMER, 2009), menciona várias questões a considerar quando se pretende negociar um acordo de fornecimento de informações eletrônicas: A) O que o vendedor possui: os dados em si ou o banco de dados compilados? B) Onde está localizado o banco de dados: no servidor do fornecedor ou é transferido para um site da instituição? C) Quem é responsável pela manutenção do banco de dados local? D) Quem pode acessar os recursos: a comunidade acadêmica, apenas a instituição, ou alunos à distância, bem como, os visitantes da biblioteca; outras bibliotecas; ou o público? Até que ponto a biblioteca é responsável por supervisionar o acesso? E) São permitidas atividades de transferência de arquivo: 0 download, imprimir, guardar, arquivamento e acesso através de um sistema de gerenciamento? F) Quem administra os direitos digitais? G) A instituição pode se tornar um fornecedor, se o acesso ao seu produto resultar em ganho financeiro? $\mathrm{H}$ ) Tem interface para iniciativas Open Source?

Os modelos de e-books atualmente no mercado, como são distribuídos, e quais os suportes necessários são questões importantes que devem ser respondidas antes da aquisição. Existem e-books com base em quatro modelos de acesso: acesso online através de navegador Internet; acesso off-line através de download no computador; download para leitura em dispositivos específico; download para leitura em disposições 

aquisição

genéricas. O artigo de Martín-González e Pivetta (2009) trata do e-book que se enquadra na categoria de acesso online a partir de dispositivos genéricos.

As principais variáveis para se levar em conta neste tipo de material (e-books) são: opções de aquisição e licença; requisitos técnicos; temas e coleções; e Digital Rights Management - DRM's. Os requisitos técnicos, embora geralmente os fornecedores disponibilizem os e-books em formato Adobe Acrobat Reader, programa este gratuito, é necessário que o fornecimento seja disponibilizado no maior número possível de programas, para atender a demanda de dispositivos utilizados pelos usuários. Na questão temas e coleções, basicamente deve-se averiguar a necessidade dos assuntos e temas que a instituição tem interesse dentro da missão estabelecida. Os DRM's verificam a administração de direitos digitais que se referem à cópia, transporte, descarga, compartilhamento e impressão do conteúdo dos e-books (MARTíN-GONZÁLEZ; PIVETTA, 2009).

Embora a gestão de coleções ajude a delinear os aspectos gerais da compra, muitas das regras normais aplicáveis para a aquisição de material impresso não são suficientes. Isto é especialmente verdadeiro com o advento de modelos de compra para e-books.

Emery e Stone (2013) aconselham a escrever um documento com especificações para a aquisição em uma única ordem. Os critérios são geralmente curtos e com base nas necessidades locais. É necessário verificar quais plataformas são as preferidas dos usuários e quais funcionam melhor no ambiente local. Outra questão é verificar se o recurso é adequado aos níveis das informações que a instituição necessita; interface intuitiva, isto é, o recurso deve ser fácil de usar; hospedagem: muitos recursos eletrônicos estão disponíveis em mais de uma plataforma; autenticação ou seja, acesso por senha; acesso irrestrito e no caso, verificar regras de acesso irrestrito. Além disso, verificar as restrições de localização (por exemplo, uso somente dentro da instituição); dados de uso: estatística de uso; capacidade de pesquisa em rede: verificar se as pesquisas são realizadas em tempo real.

Compreender as necessidades institucionais é essencial antes que se busque ecoleções no mercado e se converse com fornecedores. Verificar quais são requisitos para a interface, conteúdo e contratação do serviço também é fundamental.

Emery e Stone (2013) propõem um formulário de verificação de plataformas de serviços para aquisição de e-recursos. A primeira observação dos autores é com relação 

aquisição

a experiência do usuário que inclui: número de cliques necessários no catálogo da biblioteca para alcançar o texto completo; opções de acesso ao PDF (por exemplo, baixar, salvar, copiar e colar, impressão?), quais são os direitos de autor contra restrições de DRM? Até que ponto a aparência da interface de usuário é amigável? Quanto intuitiva são as telas para navegar (por exemplo, entre as seções / capítulos)? Capacidade para pesquisar em texto. O sistema permite que os usuários pesquisem de forma adequada para atender as suas necessidades? A plataforma deve ser interoperável com software bibliográfico. Existe a possibilidade de uso em dispositivos móveis?

Quanto ao conteúdo, Emery e Stone (2013) enfatizam que deve-se observar o que o produto oferece comparado com os temas pré-estabelecidos e com as necessidades da instituição. Deve-se verificar ainda: qual é a distribuição de datas de publicação? Há edições mais atualizadas disponíveis? Qual é a sobreposição de assinaturas existentes (por exemplo, a ebrary, Safari).

$\mathrm{Na}$ administração, Emery e Stone (2013) elencam questões cujas respostas são necessárias tais como: quanto tempo é necessário de negociação? Flexibilidade em editar os perfis (por exemplo, apenas edições atuais, possibilidade de limitação dos preços; restringir por ano; limites por tema, editor, ou série)? Como são tratados os títulos adicionais / exclusões / duplicatas? Como são tratados o monitoramento e fatura? Que métodos são utilizados para verificar o acesso? É possível fazer este monitoramento fora da instituição?

Quanto a gestão de informação, os autores destacam questões importantes: qual é o processo de notificação para as equipes de compras? Como são as informações contábeis do fundo administrado (por exemplo, frequência de relatórios, etc.)? Prestação de estatística de uso, serviço e suporte.

Neste estudo não se identificou empresas brasileiras que fornecem e-coleções especificamente para bibliotecas escolares. Mas existem algumas empresas que estão se especializando em fornecer e-materiais para bibliotecas.

\section{EMPRESAS DO MERCADO QUE OFERECEM PLATAFORMAS DE ACERVO ELETRÔNICO}

As empresas que operam no fornecimento e-coleções para bibliotecas escolares que foram apresentadas pelos autores Sathyanarayana (2013); Farmer (2009); Martín- 

aquisição

González e Pivetta (2008); Emery e Stone (2013); O’brien, Gasser e Palfrey (2012), são as seguintes:

I Empresa OverDrive ${ }^{8}$ - Principais características: mais de 1 milhão de títulos disponíveis; compatíveis com a maioria dos dispositivos da atualidade; acessibilidade remota; registros MARC para download - Modelo de negócio assinatura;

II Empresa EBSCO ${ }^{9}$ - Principais características: oferece centenas de milhares de e-book; fácil utilização; processo de download simples, e os títulos são compatíveis com a maioria dos dispositivos portáteis; relatórios de uso e desenvolvimento de coleções através de ferramentas fáceis de usar de gestão; MARC disponível sem custo para todos os títulos; disponível serviços de implementação, treinamento e suporte. - Modelo de negócio: assinatura;

III Empresa ABC-CLIO's e-book ${ }^{10}$ - Principais características: mais de 7.000 títulos já disponíveis; acesso do usuário é ilimitado e simultâneo; acessibilidade remota; apoio a citação; registros MARC para download; recursos de e-mail e impressão. - Modelo de negócio: assinatura;

IV Empresa Ebrary-eLibro ${ }^{11}$ - Principais características: hospeda 724.004 documentos; acesso a qualquer hora em qualquer lugar; compatível com vários dispositivos; acesso simultâneo; registros Marc para download. - Modelo de negócio: assinatura e aquisição perpétua;

V Empresa MyLibrary ${ }^{12}$ - Principais características: cerca de 250 mil títulos disponíveis atualmente; interface de usuário, fácil de navegar; acesso local e remoto; registros MARC para download. - Modelo de negócio: assinatura e aquisição perpétua;

\section{Empresa Safari Books online ${ }^{13}$}

- $\quad$ Principais características: mais de 36.000 livros.

- $\quad$ Modelo de negócio: assinatura.

No entanto, nem todos os editores disponibilizam seus e-books para acesso à biblioteca. A súbita popularidade dos e-readers, juntamente com a mudança para formatos digitais e das facilidades com que os clientes podem navegar e verificar e-books nos sites de bibliotecas fez com que as editoras abstivessem-se e, em alguns casos,

\footnotetext{
Disponível em: http://www.overdrive.com

Disponível em: http://www.ebscohost.com/ebooks

Disponível em: www.abc-clio.com

Disponível em: http://www.ebrary.com

Disponível em: http://www.myilibrary.com

Disponível em: http://www.safaribooksonline.com
} 

aquisição

repensassem na sua abordagem para programas de empréstimos de e-books para biblioteca (O’BRIEN; GASSER; PALFREY, 2012).

\section{MODELOS DE NEGÓCIOS PARA AQUSIÇÃO DE E-COLEÇÕES}

Para as instituições em que a licença é uma opção de aquisição de material eletrônico, sugere-se que os termos de licenciamento sejam muito bem estudados e que a biblioteca construa um termo próprio que atenda suas necessidades. O termo próprio pode proteger a biblioteca para que futuramente não ocorram situações inesperadas que possam prejudicar o atendimento aos usuários da biblioteca, como por exemplo, uma interrupção, de fornecimento do serviço.

Bosch (2005) apresenta algumas recomendações e questionamentos que devem ser observados pela biblioteca no momento de contratação de um serviço que disponibilize material eletrônico. O licenciamento de recursos eletrônicos tornou-se uma atividade importante para todas as partes envolvidas na produção, compra e entrega desses recursos. Muitos modelos de licença de recursos foram construídos, mas é de suma importância que as bibliotecas prestem atenção no uso de modelo de licenças notadamente em relação a alguns princípios $(\mathrm{BOSCH}, 2005)$.

A licença de materiais eletrônicos tem se tornado uma das melhores práticas para o processo de acesso aos documentos eletrônicos. Muitas licenças sugerem que cada biblioteca deva ter uma lista preparada de direitos básicos que devem ser incluídos em uma licença. Bosch (2005) observa que se esses direitos não forem atendidos, o produto não deve ser adquirido.

Defende ainda Bosch (2005) a ideia que se a biblioteca possuir um modelo de licença é mais fácil a negociação com o fornecedor no momento da aquisição do material eletrônico. No processo de licenciamento, ambos os editores e bibliotecários, devem definir suas necessidades e estabelecer políticas.

Muitos modelos de licenciamento foram construídos desde 1990. Em 2000 cinco agentes de assinaturas (Blackweel/Swets, Dawson Information Service Group, EBSCO, The Faxon Company, e Harrassowitz) trabalharam com um grupo de bibliotecários e o especialista em modelos de licença John Cox. Esse trabalho resultou na criação de um conjunto de quatro licenças para diferentes tipos de bibliotecas, sendo estas: bibliotecas 

aquisição

acadêmicas; consórcios de bibliotecas; bibliotecas públicas; e bibliotecas especializadas e de empresas (BOSCH, 2005).

Para Bosch (2005), os modelos de licenças que são desenvolvidos em bibliotecas proporcionam muitos benefícios destacando-se que: modelos de licenças são ferramentas de comunicação eficientes; o processo de desenvolvimento de modelos melhora a compreensão dentro uma organização; modelos de licenças utilizam uma linguagem comum; eles fornecem eficiência em relação à gestão das licenças; o processo de revisão é simplificada; a edição de modelos de documentos é mais fácil e a responsabilidade legal é reduzida.

Um modelo de licença para Bosch (2005) deve conter os seguintes termos: 1. Quem está participando da licença, tanto o licenciado como o licenciador; 2. O que está sendo licenciado, o seu custo, bem como o prazo para a licença; 3. Direitos necessários básicos, lembrando que todos os direitos devem ser especificadamente incluídos no contrato, a licença deve incluir uma lista que permita aos usuários: a) acessar o produto; b) procurar o produto; c) obter resultados de busca; d) rever e fazer download de informações a partir dos resultados da pesquisa; e) imprimir informações em cópia impressa a partir dos resultados da pesquisa; f) obter resultados de pesquisa em formato eletrônico por um período g) compartilhar resultados de busca com outros usuários autorizados; h) preservar os direitos autorais;

O modelo, de acordo com o autor citado, deve incluir termos de direitos que poderiam ser considerados "desejados". Algumas destas áreas podem ser consideradas obrigatórias por alguns bibliotecários:

a) assinatura contínua de acesso a materiais ou arquivamento, fornecida pelo editor ou uma fonte de intermediário; b) empréstimo entre bibliotecas; c) reservas eletrônicas; d) pacotes de curso eletrônico e acesso remoto para alunos à distância.

Bosch (2005) ainda observa que certos tipos de proibições para preservar os direitos autorais podem negar ao usuário a capacidade de: a) carregar os materiais licenciados em seu servidor ou em qualquer outro lugar; b) sistematicamente fazer cópias eletrônicas de matérias licenciados, sejam temporárias ou permanentes; c) remover ou alterar os nomes dos autores ou o editor de avisos de direitos autorais ou outros meios de identificação como eles aparecem nos materiais licenciados; d) fazer impressão eletrônicas ou conjunto de cópias de uma significativa parte dos materiais licenciados para qualquer finalidade; e) disponibilizar ou distribuir qualquer parte do material 

aquisição

licenciado em qualquer rede eletrônica, incluindo a internet; f) usar toda ou qualquer parte dos materiais licenciados com finalidade comercial; g) usar toda ou qualquer parte dos materiais licenciados para desenvolver um banco de dados, infobase ou outro recurso de informação para revenda, reutilização ou sublicenciar; h) alterar, condensar, adaptar, modificar, traduzir, ou fazer qualquer trabalho derivado que traga qualquer alteração para no material licenciado.

Obrigações ou cometimento também é uma observação que deve ser feita segundo Bosch (2005), pois a função normal de um acordo de licença é para obrigar uma das partes a atividades específicas. Ambas as partes devem considerar essas obrigações como significativas e estarem preparadas para cumprir os termos escritos. Obrigações potenciais sobre a parte da biblioteca ou licenciado pode incluir: registro de usuários autorizados nos termos aprovados pelo licenciante; notificação de mudança na lista usuários autorizado; notificação de adições e exclusões de IP; retenção de reserva eletrônica, registros de curso para revisão licenciante; remoção de conteúdo licenciado de e-reservas ou conteúdo de curso; notificação imediata de qualquer violação da licença; notificação imediata de rescisão do contrato ou aviso de exigência financeira.

Alguns termos que Bosch (2005) denomina como gerais devem ser observados, tais como: a) o processo de alteração da licença; b) o processo usado para encerrar a licença; c) resolução de litígios; d) lei aplicável; e) procedimento para a classificação em caso de venda do fornecedor; f) falha de desempenho.

Para Sathyanarayana (2013), no mundo de material impresso, a função do desenvolvimento de coleção girava em torno da filosofia da biblioteca e a preservação de uso. A aquisição era perpétua, já no mundo de e-conteúdo, os editores tomaram o controle do direito do conteúdo, da propriedade, da entrega e do uso por meio do ciclo de vida legal até a expiração dos direitos de copyright. $O$ processo de obtenção $e$ manutenção, o direito de acesso, que é conhecido como o licenciamento, estão gradualmente substituindo a aquisição tradicional de conteúdo de compra (SATHYANARAYANA, 2013).

O autor observa ainda que o propósito do desenvolvimento de coleção no ambiente eletrônico deve ser redefinido. Esta nova missão de desenvolvimento de coleção eletrônica forçará algumas alterações. O desenvolvimento de coleções se tornará em um curto prazo, em um plano de retenção permanente de licenciamento para um definitivo ou não definitivo, período de acesso e uso. Mudará o foco do investimento de propriedade de 

aquisição

conteúdo para a preservação do fornecimento de tecnologia, infraestrutura que melhorará o acesso, a entrega e valor de uso do conteúdo licenciado.

Ainda de acordo com Sathyanarayana (2013) e O’brien, Gasser e Palfrey, (2012) muitos modelos de negócios estão evoluindo em várias permutações e combinações em torno do novo processo de e-aquisição de conteúdo. Esses modelos podem controlar o acesso no que se refere ao volume de conteúdo, duração do acesso, o tamanho da população de usuários e os dispositivos de computação utilizados para o acesso.

Os modelos de distribuição variam, e os e-books são mais comumente disponíveis para bibliotecas através de um distribuidor intermediário (por vezes denominado como um "agregador"), que vende o acesso a títulos de e-books e cópias de e-books, muitas vezes de vários editores. É interessante notar que há algumas editoras que vendem diretamente e-books para bibliotecas, mas a percentagem global é relativamente pequena (O'BRIEN; GASSER; PALFREY, 2012).

Os distribuidores fornecem e-books para as bibliotecas mediante modelos de negócios, cujos mais utilizados são os descritos a seguir.

a) Direito perpétuo de acesso: esse modelo é semelhante a compra de livros e revistas no modelo de impressão em bibliotecas. A biblioteca pode licenciar o conteúdo que concede direitos de acesso pela sua comunidade de usuários por um período ilimitado. Tecnicamente isso significa que a biblioteca tem os direitos de acesso durante toda a sua vida organizacional (SATHYANARAYANA, 2013).

b) Direito de acesso por período limitado: esse modelo é semelhante ao arrendamento ou locação dos direitos de acesso para um período limitado, que pode variar de um mês a um ano ou mais. Pelo entendimento geral, a biblioteca deixará de ter direito de acesso ao conteúdo no momento em que o período de concessão expirar (SATHYANARAYANA, 2013).

c) Modelo de assinatura: esse modelo é conhecido por ser semelhante à assinatura impressa de revistas já existente em bibliotecas, com variações no direito de acesso. No caso, os distribuidores oferecerem acesso a um grande banco de dados de títulos de ebooks por um pré-determinado período de tempo, geralmente em uma base anual. É o modelo mais confuso, tendo em vista as diferentes condições de comercialização, o que demanda muita atenção por parte dos bibliotecários (SATHYANARAYANA, 2013; O’BRIEN; GASSER; PALFREY, 2012). 

aquisição

d) Modelo de licenciamento: dependendo dos termos da licença, o e-book pode ser "emprestado" por meio da plataforma de software para os clientes por um período determinado de tempo estabelecido pelo fornecedor, o editor, ou a biblioteca. Na maioria dos casos, o empréstimo de e-books é ativada pela tecnologia de DRM, que limitam a maneira em que o arquivo pode ser acessado e compartilhado. $O$ uso pode ser simultâneo ou não, depende do tipo de licença adquirida pela biblioteca (O'BRIEN; GASSER; PALFREY, 2012).

e) Modelo Pay-per-view: esse modelo é equivalente ao serviço de entrega de documentos pagos, no qual o usuário pode ser uma biblioteca que paga e recebe 0 documento. Este sistema começou a ser oferecido na era eletrônica. As bibliotecas pagam uma taxa para exibir uma lista de títulos para os clientes, mas a biblioteca deve "alugar" cópias individuais a partir deste banco de dados com uma taxa adicional por cópia. Ao contrário do modelo de assinatura, que dá acesso a muitos títulos mediante o pagamento de uma alta taxa anual - alguns dos quais não podem ser usados pelos usuários - esta taxa, no modelo Pay -per-view, é muito menor do que a cobrada no modelo de assinatura.

Dois elementos são, portanto, determinantes no desenvolvimento de e-coleções: os direitos adquiridos para o acesso com base no modelo de negócio da editora escolhido pela biblioteca; e um documento descrevendo os termos de contrato de licenciamento em que esses direitos são adquiridos.

\section{CONSIDERAÇÕES FINAIS}

A realização desse estudo evidenciou a necessidade de haver mais estudos sobre esse tema na literatura brasileira, pois se novas e mais pesquisas forem realizadas acerca do assunto, será possível uma contratação de serviços que ofereçam materiais eletrônicos para bibliotecas com maior facilidade de escolha e possibilidade de se estabelecer cláusulas que possam proteger e beneficiar ambos os fornecedores e os consumidores do serviço.

As informações apresentadas e analisadas nesse artigo podem ajudar a entender melhor o ecossistema que envolve uma compra ou um contrato de licenciamento de eacervos. Muitos dos exemplos citados não são especificamente desenvolvidos para 

aquisição

bibliotecas escolares, mas servem para orientação com relação aos detalhes que devem ser considerados na compra ou contratação de materiais eletrônicos.

Os critérios para avaliação e seleção de materiais apresentados na literatura são realmente um direcionamento para quem está iniciando uma coleção eletrônica, devendo o bibliotecário prestar atenção inicial e, principalmente, na missão da sua instituição; na comunidade na qual a biblioteca está inserida, de modo a atender os seus objetivos; o orçamento que este profissional tem disponível; os recursos tecnológicos necessários para implementar essa atividade e o pessoal treinado para disponibilizar o serviço.

Quanto às empresas que disponibilizam e-acervos para bibliotecas, nesse estudo não foi possível elencar empresas brasileiras, e há, portanto, necessidade de realização de um novo trabalho, posteriormente, para alcançar esse objetivo. Mesmo assim foram elencadas empresas que prestam esse serviço internacionalmente e dessa forma podem atender a demanda de material internacional nas bibliotecas brasileiras.

Nesse texto, utilizou-se em várias oportunidades o termo e-acervos, e-coleções ou e-materiais, pois constatou-se que embora os e-books possuam características próprias, os mesmos cuidados que devem ser tomados para se adquirir outras publicações eletrônicas, se aplicam aos e-books.

Por fim, considerando-se que a aquisição de materiais de informação pode ser vista sob uma perspectiva de processo ou de política, acredita-se que os objetivos propostos por esse trabalho foram alcançados, visto que foram compiladas informações relevantes que servirão de base para elaboração de uma política de aquisição de uma ecoleção ou mais especificamente de e-books.

\section{REFERÊNCIAS}

AGUADO DE COSTA, A. Gestíon de colecciones. Argentina: Alfagrama, 2011. 152p.

AQUINO, M. A. Metamorfoses da cultura: do impresso ao digital, criando novos formatos e papéis em ambientes de informação. Ciência da Informação, Brasília, v. 33, n. 2, p. 714, maio/ago. 2004. Disponível em: <http://www.scielo.br/pdf/ci/v33n2/a01v33n2.pdf>. Acesso em: 17 nov. 2013. 
Ivone Guerreiro Di Chiara; Elaine Cristina Liviero Tanzawa

Os e-books nas coleções de bibliotecas escolares: subsídios para elaboração da política de aquisição

BALL, D. Positioning librarians as essential to the new virtual learning. In: ANNUAL INTERNATIONAL ASSOCIATION OF TECHNOLOGICAL UNIVERSITY LIBRARIES, 27., 2006, Porto. Proceeding... Porto: International Association of Technological University Libraries, 2006. p.10-19. Disponível em: <http://eprints.rclis.org/7906/>. Acesso em: 07 maio 2013.

$\mathrm{BOSCH}$, Stephen. Using model licenses. Journal of Library Administration, London, v. 42, n. 3/4, p. 65-81, 2005. Disponível em:

<http://web.ebscohost.com.vlib.interchange.at/ehost/pdfviewer/pdfviewer?vid=3\&sid=a7dc bdfa-f2b3-42dd-82a0-eb99de1a778a@sessionmgr4002\&hid=4109>. Acesso em: 17 nov. 2013.

BRASIL. Lei 12244 de 24 de maio de 2010. Dispõe sobre a universalização das bibliotecas nas instituições de ensino do País. Diário Oficial [da] República Federativa do Brasil, Brasília, 25 maio 2010. Disponível em:

<https://www.planalto.gov.br/ccivil_03/_ato2007-2010/2010/lei/l12244.htm> Acesso em: 31 mar. 2013.

CORBETT, T. The changing role of the school library's physical space. School Library Monthly, Lincoln, n. 7, p. 5-7, Apr. 2011. Disponível em: <http://www.schoollibrarymonthly.com/articles/Corbett2011-v27n7p5.html>. Acesso em: 17 nov. 2013.

CUNHA, M. B. Desafios na construção de uma biblioteca digital. Ci. Inf., Brasília, n. 3, v. 28, p. 257-268, set./dez. 1999. Disponível em:

<http://www.scielo.br/pdf/ci/v28n3/v28n3a3.pdf>. Acesso em: 14 ago. 2013.

DIAS, G. D.; SILVA, T. E.; CERVANTES, B. M. N. Política de desenvolvimento de coleções para documentos eletrônicos: tendências nacionais e internacionais. Encontros Bibli, Florianópolis, v. 17, n. 34, p.42-56, maio./ago. 2012. Disponível em:

<https://periodicos.ufsc.br/index.php/eb/article/view/1518-2924.2012v17n34p42/22652>. Acesso em: 29 ago. 2013.

EMERY, J.; STONE, G. Investigation of new content. Library Technology Reports, New York, v. 49, n. 2, p.10-15, fev./mar. 2013. Disponível em:

<http://vlib.interchange.at/login?url=http://web.ebscohost.com/ehost/pdfviewer/pdfviewer?v $\mathrm{id}=4 \&$ sid=4aed0fb4-0312-431c-92a5-1845a89dbd93@sessionmgr4003\&hid=4204>. Acesso em: 07 jan. 2014.

EVANS, G. E.; SAPONARO, M. Z. Development library and information center collections. $5^{\text {th }}$. London: Libarries unlimited, 2005. 446p.

FARMER, L. S. J. The life cycle digital reference sources. The Reference Librarian, New York, v. 50, n. 9, p. 117-135, 2009. Disponível em:

<http://vlib.interchange.at/login?url=http://web.ebscohost.com/ehost/pdfviewer/pdfviewer?v $i d=3 \&$ sid $=723 b 97 e b-b a 5 e-46 f d-91$ ef-a6bca6fbc291\%40sessionmgr4001\&hid=4207> .

Acesso em: 03 jan. 2014. 
Ivone Guerreiro Di Chiara; Elaine Cristina Liviero Tanzawa

Os e-books nas coleções de bibliotecas escolares: subsídios para elaboração da política de aquisição

FERREIRA ,S. M. S. P. Design de biblioteca virtual centrado no usuário: a abordagem do Sense-Making para estudos de necessidades e procedimentos de busca e uso da informação. Ciência da Informação, Brasília, v. 26, n. 2, maio/ago. 1997. Disponível em: <http://www.scielo.br/scielo.php?script=sci_arttext\&pid=S0100-19651997000200014>. Acesso em: 05 fev. 2014.

\section{GIL, A. C. Métodos e técnicas de pesquisa social. São Paulo: Atlas, 1999. 201p.}

INTERNATIONAL FEDERATION OF LIBRARY ASSOCIATIONS AND INSTITUTIONS. Manifesto IFLA/UNESCO para biblioteca escolar. 2000. Disponível em: <http://archive.ifla.org/VII/s11/pubs/portuguese-brazil.pdf>. Acesso em: 19 jun. 2013.

KHAN, S. I.; KHAN, M. A. Collections development of maulana azad library (amu) and central library of university of delhi: a comparative study. BJIS, Marília, v. 4, n. 2, dez. 2010. Disponível em:

<http://www2.marilia.unesp.br/revistas/index.php/bjis/article/view/486/768>. Acesso em: 10 dez. 2013.

LASTRES, S. A. Collection development in age of the virtual law firm library: how to expand your footprint beyond your wall. AALL Spectrum, Chicago, v. 15, n.8, p. 20-23, jun. 2011. Disponível em:

<http://vlib.interchange.at/login?url=http://web.ebscohost.com/ehost/pdfviewer/pdfviewer?v $\mathrm{id}=3 \&$ sid=5adb082b-9fa4-41cf-818a-4a1e9570a91e@sessionmgr4003\&hid=4209> .

Acesso em: 2 jan. 2014.

LYNCH, C. A. Ebooks in 2013: promises broken, promises kept, and faustian bargains.

American Libraries Magazine, Washington, p. 12-16, Jun. 2013. Disponível em: <http://www.americanlibrariesmagazine.org/>. Acesso em: 29 nov. 2013.

MARTÍN-GONZÁLES, J. C.; PIVETTA, E. Factores clave en el proceso de adquisición de libros electrónicos. El Profesional de La Información, Barcelona, v. 4, n. 17, p.408-413, jul. 2009. Disponível em:

<http://vlib.interchange.at/login?url=http://web.ebscohost.com/ehost/pdfviewer/pdfviewer?v $\mathrm{id}=3 \&$ sid=16083dbc-45b8-49a8-b86e-f57a63a8b2a0@sessionmgr4005\&hid=4114>.

Acesso em: 05 jan. 2014.

MARX, A. W. E-books and democracy. The New York Times, New York, p. 1-3. 01 maio 2013. Disponível em: <http://www.nytimes.com/2013/05/01/opinion/e-books-libraries-anddemocracy.html?_r=0>. Acesso em: 07 maio 2013.

O'BRIEN, D. R.; GASSER, U.; PALFREY, J. E-books in library: a briefing document development in preparation for a workshop on E-lending in library. Berkman, Cambridge, v. 1, n. 111, p.1-24, 2012. Disponível em:

<http://cyber.law.harvard.edu/sites/cyber.law.harvard.edu/files/E-

Books\%20in\%20Libraries\%20(O'Brien,\%20Gasser,\%20Palfrey)-1.pdf>. Acesso em: 10 jan. 2014.

PROCÓPIO, E. Construindo uma biblioteca digital. São Paulo: Edições Inteligentes, 2005. 

aquisição

SATHYANARAYANA, N. V. Collection development in the e-content world: challenges of procurement, access and preservation. Desidoc: Journal of Library \& Information Technology, v. 2, n. 33, p.109-113, mar. 2013. Disponível em:

<http://vlib.interchange.at/login?url=http://web.ebscohost.com/ehost/pdfviewer/pdfviewer?v id=4\&sid=c601ebfe-9249-42cf-8f6e-f8ab7b60f5cd@sessionmgr4001\&hid=4101 >. Acesso em: 29 nov. 2013.

SHERMER-SHALMAN, Z. Web sites and digital services in Israeli school libraries: how is a digital environment changing how school libraries work? School Libraries Worldwide, Israel, v. 14, n.1, p. 86-98, jan. 2008. Disponível em: <https://www.questia.com/read/1P31510667011/web-sites-and-digital-services-in-israeli-school-libraries>. Acesso em: 06 jan. 2014.

SILVA, G. M. S.; BUFREM, L. S. Livro eletrônico: a evolução de uma ideia. In: CONGRESSO BRASILEIRO DA COMUNICAÇÃO, INTERCOM, 24., 2001, Campo Grande. Anais eletrônicos... Campo Grande: Intercom, 2001. p. 1-16. Disponível em: <http://www.intercom.org.br/papers/nacionais/2001/papers/NP4BUFREM.pdf>. Acesso em: 10 jan. 2014.

SILVA, J. L. C. Perspectivas históricas da biblioteca escolar no Brasil e análise da Lei 12.244/10. Revista ACB: Biblioteconomia em Santa Catarina, Florianópolis, v. 16, n. 2, p. 489-517, jul./dez. 2011. Disponível em:

<http://revista.acbsc.org.br/racb/article/view/797/pdf_63>. Acesso em: 10 jan. 2014.

STRIPLING, B. et al. ALA, future of libraries: digital content, and ebooks. American Libraries Magazine, Washington, p.5-7, jun. 2013. Disponível em: <http://www.americanlibrariesmagazine.org/>. Acesso em: 29 nov. 2013.

VERGUEIRO, W. Desenvolvimento de coleção. São Paulo: Polis, 1989.

WEITZEL, S. R. Elaboração de uma política de desenvolvimento de coleções em bibliotecas universitárias. 2. ed. Rio de Janeiro: Interciência, 2013.

Rio de Janeiro: Interciência, 2006. 76p.

\section{Title}

E-Books in the Collections of School Libraries: Subsidies for development of the acquisition policy

\section{Abstract}

Introduction: The electronic document as new informational support is requiring changes in libraries related to the acquisition policy as well as the need to collect funding for development of that policy, what motivated this study.

Objective: To establish funding to assist in the development of e-book acquisition policy for school libraries. 

aquisição

Methodology: bibliographic research using as sources the most important databases in the area of Information Science. The selected texts were journal articles, books, theses, dissertations and papers presented at events from 2000 to 2013.

Results: It was possible to identify all the care to be taken when purchasing e-collections, especially in licensing contracts, suppliers and business models used for the acquisition of this type of material, mainly e-books.

Conclusions: The information presented and analyzed may contribute for development of a policy of acquiring e-books, considering that although this support has its own characteristics, procedures for acquisition of materials that compose the e-collections are similar.

Keywords: Electronic books. Collection development policy. Acquisition policy. Planning electronic collections. School libraries.

\section{Título}

E-libros en las colecciones de bibliotecas escolares: subvenciones para la elaboración de la política de contratación

\section{Resumen}

Introducción: El documento electrónico como nuevo soporte informacional ha exigido a las bibliotecas cambios en el método de adquirir y también la necesidad de obtener subsidios para elaborar ese método, lo que motivó este estudio.

Objetivo: Establecer los subsidios que ayuden en la elaboración de este método para adquisición de los e-books, en las bibliotecas escolares.

Metodología: pesquisa bibliográfica que tiene como fuentes las bases de datos más importantes del área de la Ciencia de la Información. Los textos seleccionados fueron artículos de periódicos, libros, tesis, disertaciones y trabajos presentados en eventos desde el 2000 al 2013.

Resultados: Se identificó todos los cuidados que se debe tener al realizar la adquisición de ecolecciones, especialmente en los contratos de licencia, los proveedores y los modelos de negocio utilizados para adquirir este tipo de material, principalmente e-books.

Conclusiones: Las informaciones presentadas y analizadas podrán servir como subsidios para la elaboración de un método para adquirir los e-books, teniendo en cuenta que a pesar de que este apoyo tiene sus propias características, los procedimientos para adquirir los materiales que componen las e-colecciones, son similares.

Palabras clave : Libros electrónicos. Política de desarrollo de la colección. Política de adquisiciones. La planificación de colecciones electrónicas. Las bibliotecas escolares.

Recebido em: 12.11.2014

Aceito em: 22.12.2014 